\title{
PERANCANGAN PROGRAM APLIKASI TABUNGAN MENGGUNAKAN SERVER NGINX (Studi Kasus Madrasah Ibtidayah Negeri 01 Kota Bengkulu)
}

\author{
Ardi Wijaya $^{1}$, Army Martia Harjuna ${ }^{2}$ \\ ${ }^{1,2}$ Program Studi Informatika, Fakultas Teknik, Universitas Muhammadiyah Bengkulu \\ Jl. Bali PO BOX 118. Telp (0736) 227665, Fax (0736) 26161, Bengkulu 38119 \\ 1ardi_wijaya18@yahoo.co.id \\ ${ }^{2}$ saya.army@yahoo.com
}

\begin{abstract}
Abstrak: Madrasah Ibtidayah Negeri 01 Kota Bengkulu merupakan pendidikan setingkat sekolah dasar. Sistem pengelolaan data tabungan yang berjalan saat ini masih dikerjakan secara manual pencatatan dan penyimpanan data ditulis di dalam buku, dan perhitungannya masih dikerjakan dengan alat bantu kalkulator. Hasil analisis menunjukkan bahwa kekurangan sistem yang sudah berjalan menunjukan adanya kekurangan pada bagian perangkat lunak untuk membantu pengelolaan data. Pada penelitian ini akan dibangun sebuah sistem basis data yang menggunakan server NGINX. NGiNX adalah sebuah server HTTP dan reserve proxy gratis berbasis open-source. Maka dari itu penelitian ini dianggap perlu untuk merancang suatu sistem yang dapat mempermudah proses pendataan dan penyimpanan, sehingga informasi yang ingin didapat nanti akan berjalan dengan cepat dan akurat.
\end{abstract}

Kata kunci: Perangkat Lunak, Tabungan Sekolah, NGINX

Abstract: Madrasah Ibtidayah Bengkulu City State 01 is an education equal to elementary schools. Data Management Sistem That Runs savings previously worked Still Operates Currently the recording and storage of data written in the hearts of books, and the calculation is still done WITH Calculator tools. The analysis showed that the shortage Sistem Already Running AT deficiency showed a Software section to review helps manage data. AT research will Husband built a database sistem using Server nginx Yang. Nginx is a HTTP server and the backup proxy-based open-source free. From ITU Research singer then considered Need to review devise a sistem that can facilitate the process of data collection and storage, so that information obtained Later Who Wants to be running fast and accurate.

Keywords: Software, Saving School, nginx.

\section{PENDAHULUAN}

Pada dasarnya pekerjaan pengolahan data tabungan siswa setiap harinya bukan tidak mungkin dilakukan secara manual, akan tetapi mengingat permasalahannya adalah media penyimpanan data tidak terkomputerisasi dan masih berupa arsip, sehingga dalam pencarian data membutuhkan waktu yang lama karena harus mencari dan mencocokan dengan arsip, Selain itu petugas juga memiliki kesulitan dalam hal pencarian data nasabah, penghapusan dan pengeditan data tabungan.

Adapun dalam pembuatan laporan tabungan sering mengalami kendala seperti dalam perhitungan yang sering mengalami kesalahan, sehingga memerlukan perhitungan ulang. Kemudian dalam rekapitulasi laporan tabungan yang dilakukan setiap harinya dan ditulis secara manual didalam buku tabungan siswa, hal tersebut tentunya akan menjadi masalah bagi petugas apabila form laporan semakin banyak, dalam pengerjaannya akan memerlukan banyak orang. 
Dari permasalahan di atas, penulis mencoba membangun aplikasi yang diharapkan dapat membantu petugas dalam pengentrian data ataupun pencarian data, sehingga informasi yang dibutuhkan dapat dengan cepat dan akurat.. Maka penulis mengusulkan untuk membuat atau merancang sebuah sistem tabungan yang komputerisasi agar dapat membantu menyelesaikan permasalahan diatas dengan judul “PERANCANGAN PROGRAM APLIKASI TABUNGAN MENGGUNAKAN SERVER NGINX”.

\section{TINJAUAN PUSTAKA}

\section{A. Penelitian Terkait}

Septika Hapsari dkk, melakukan penelitian Tujuan utama dari penelitian ini adalah menyajikan Sistem Informasi yang dapat digunakan agar sesuai dengan kebutuhan. Desain sistem baru menggunakan teknik terstruktur dimana sistem dimodelkan dengan diagram aliran data, database dimodelkan dengan menggunakan Entity Relationship Diagram (ERD). Penelitian ini menghasilkan aplikasi untuk Sistem Pembayaran iuran sekolah, tabungan siswa dan pelaporan untuk Sekolah Menangah Kejuruan (SMK) Negeri Pringkuku. Dan dengan sistem baru dapat mengoptimalkan sistem komputer yang ada dalam proses pembayaran iuran sekolah, tabungan siswa dan pelaporan sehingga dapat mengelola data dengan baik, untuk menghasilkan informasi yang lebih mudah dan akurat [1].

Hendra Purnama [2], juga melakukan penelitan yang terkait. sistem yang berjalan saat ini masih dikerjakan secara manual, pencatatan dan penyimpanan data ditulis di dalam buku dan perhitungannya masih dikerjakan secara konvesional dan data di simpan dalam bentuk arsip, sehingga besar kemungkinan untuk hilangnya buku arsip, terkena air hujan, terbakar, dan lain-lain. Penyebab masalah ini dikarenakan belum adanya aplikasi untuk menampilkan data yang dibutuhkan, hal ini dapat menyebabkan kesulitan dalam menyajikan informasi. Oleh karena itu, diperlukan sistem informasi pengelolaan data tabungan siswa, sehingga memudahkan petugas dalam pengelolaan data serta perhitungan tabungan siswa tersebut dan pendataan tabungan yang akurat. Untuk meminimalisir permasalahan diatas, maka data pengelolaan data tabungan dilakukan secara terkomputerisasi dan tersimpan pada basis data [2].

\section{B. Sistem Basis Data}

Sistem adalah sebuah tatanan (keterpaduan) yang terdiri atas sejumlah komponen fungsional (dengan satuan fungsi dan tugas khusus) yang saling berhubungan dan secara bersama-sama bertujuan untuk memenuhi suatu proses tertentu.

Basis data hanyalah sebuah objek yang pasif. Ia ada karena ada pembuatnya. Ia tidak akan pernah berguna jika tidak ada pengelola dan penggeraknya. Yang menjadi pengelola dan penggeraknya secara langsung adalah program/aplikasi (software). Gabungan keduanya (basis data dan pengelolanya menghasilkan sebuah sistem.

Karena itu, secara umum sebuah Sistem Basis Data merupakan sistem yang terdiri atas kumpulan tabel data yang saling berhubungan (dalam sebuah basis data di sebuah sistem komputer) dan sekumpulan program (yang bisa disebut DBMS/Data Base Management Sistem) yang memungkinkan beberapa pemakai atau program lain untuk mengakses dan memanipulasi tabeltabel data tersebut [3]. 
Jurnal Pseudocode, Volume IV Nomor 1, Februari 2017, ISSN 2355-5920

www.ejournal.unib.ac.id/index.php/pseudocode

C. Tabungan

Pengertian tabungan menurut Undang-undang no. 10 tahun 1998 tentang perbankan atas undangundang no. 7 tahun 1992 tentang perbankan pasal 1 ayat 9: "Merupakan simpanan yang penarikannya dapat dilakukan menurut syarat tertentu yang disepakati tetapi tidak dapat ditarik dengan cek atau alat yang dipersamakan dengan itu”.

\section{Web Server}

Web server adalah perangkat lunak yang menjaditulang belakang dari world wide web (www). Webserver menunggu permintaan dari client yang menggunakan browser seperti Netscape Navigator,Internet Explorer, Mozilla, dan program browser lainnya. Jika ada permintaan dari browser, maka web server akan memproses permintaan itu kemudian memberikan hasil prosesnya berupa data yang diinginkan kembali ke browser [4].

\section{E. Nginx}

Dimitri Aivaliotis mengemukakan bahwa Nginx pertama kali disusun menjadi HTTP. Nginx merupakan salah satu software web server yang powerful dan mempunyai performa tinggi, selain itu Nginx juga di desain untuk server dengan sumber daya yang kecil. Nginx di rancang untuk mengatasi masalah $\mathrm{C} 10 \mathrm{~K}$ yang dijelaskan oleh Daniel Kegel di(http://www.kegel.com/c10k.html). Maksud dari C10K adalah merancang web server untuk menangani 10.000 koneksi simultan, Nginx juga mampu melakukan hal ini melalui mekanisme event-based connection-handling, tetapi harus menggunakan sistem operasi yang mendukung mekanisme tersebut [5].

\section{F. Flow Chart}

Flowchart atau bagan alir adalah representasi grafik dari sistem yang mendeskripsikan relasi fisik di antara entitas-entitas intinya. Bagan alir dapat digunakan untuk menyajikan aktivitas manual, aktivitas pemrosesan komputer, atau keduanya.
Bagan alir dokumen (dokumen flowchart) digunakan untuk menggambarkan elemen-elemen dari sistem manual, termasuk catatan akuntansi departemen organisasi yang terlibat dalam proses dan aktivitas yang dilakukan dalam departemen tersebut [6].

\section{G. Data Flow Diagram (DFD)}

Data Flow Diagram merupakan diagram yang menggunakan notasi-notasi untuk menggambarkan arus dari data sistem. DFD sering digunakan untuk menggambarkan suatu sitem yang telah ada atau sistem baru yang akan dikembangkan secara logika tanpa mempertimbangkan lingkungan fisik dimana data tersebut mengalir. Diagram Arus Data (Data Flow Diagram) adalah gambaran grafis yang memperlihatkan aliran data dari sumbernya. Dalam objek kemudian melewati suatu proses yang menstransformasinya ke tujuan yang lain, yang ada pada objek lain [6].

\section{H. Entity Relationship Diagram (ERD)}

ERD ( Entity Relation Diagram )merupakan suatu model untuk menjelaskan hubungan antar data dalam basis data berdasarkan objek-objek dasar data yang mempunyai hubungan antar relasi. ERD untuk memodelkan struktur data dan hubungan antar data, untuk menggambarkannya digunakan beberapa notasi dan symbol [1].

\section{METODE PENELITIAN}

\section{A. Teknik Pengumpulan Data}

Metode penelitian dalam penyusunan penelitian ini adalah metode pengumpulan data. Metode ini bertujuan untuk mendukung dalam memperoleh informasi yang dibutuhkan dalam rangka mencapai tujuan penelitian. Tujuan yang dimaksudkan dalam bentuk hipotesis merupakan jawaban sementara terhadap pertanyaan penelitian, yang merupakan elemen penting dalam penelitian. Teknik pengumpulan data yang benar akan menghasilkan 
Jurnal Pseudocode, Volume IV Nomor 1, Februari 2017, ISSN 2355-5920

www.ejournal.unib.ac.id/index.php/pseudocode

hasil perbandingan dari apa yang diteliti sebelumnya. Adapun metode pengumpulan data yang digunakan bersumber dari:

a. Pengamatan (Observasi)

Melakukan pengamatan langsung pada objek penelitian.

b. Wawancara (interview)

Dalam metode ini melakukan tanya jawab langsung kepada pihak-pihak yang terkait, guna mendapatkan data yang dibutuhkan dalam penelitian ini.

c. Studi Pustaka

Studi literature,catatan dan laporan, menggunakan pengetahuan teoritis yang didapat jurnal penelitian serta memperlajari buku-buku literatur yang berhubungan dalam penulisan penelitian ini.

\section{B. Desain Sistem}

1. FlowChart

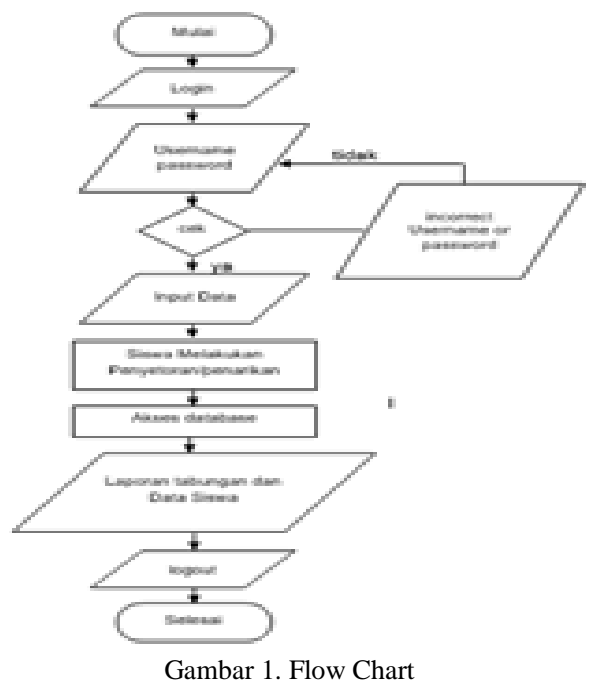

2. Context Diagram

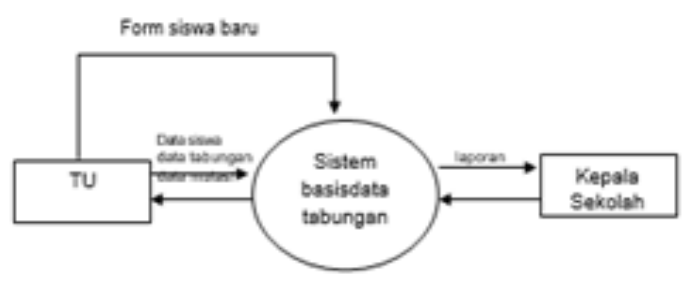

Gambar 2. Context Diagram
3. DFD (Data Flow Diagram)

1. DFD level 0

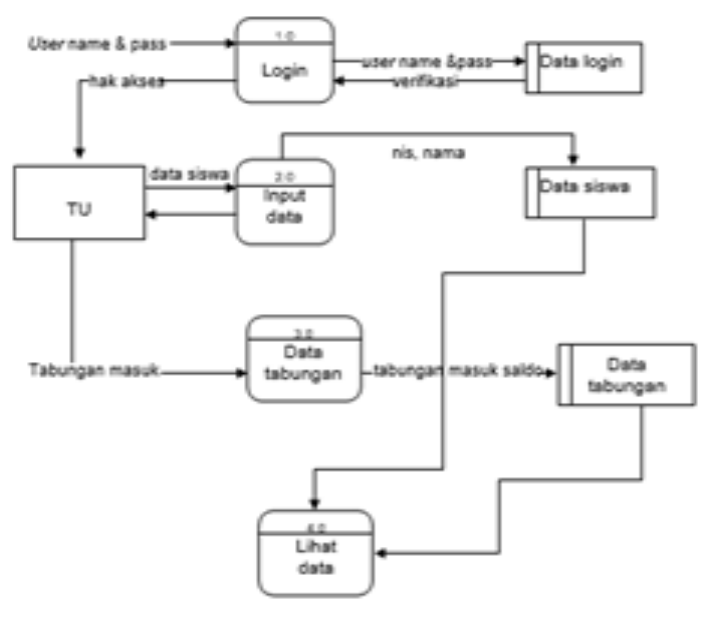

Gambar 3. DFD Level 0

2. DFD level 1 proses Input data

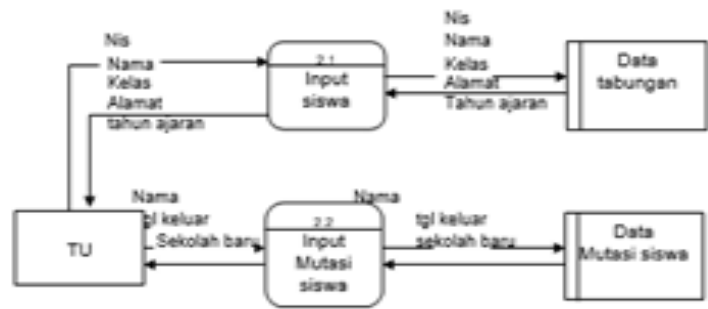

Gambar 4. DFD Level 1 Proses Input Data 3. DFD Level 1 Proses Tabungan

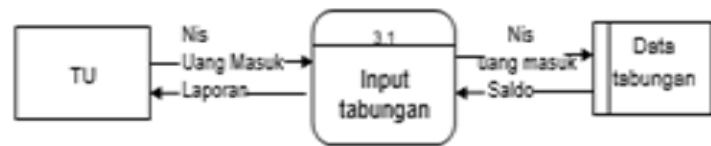

Gambar 5. DFD Level 1 Proses Tabungan

C. Model Perancangan Database ERD Tabungan

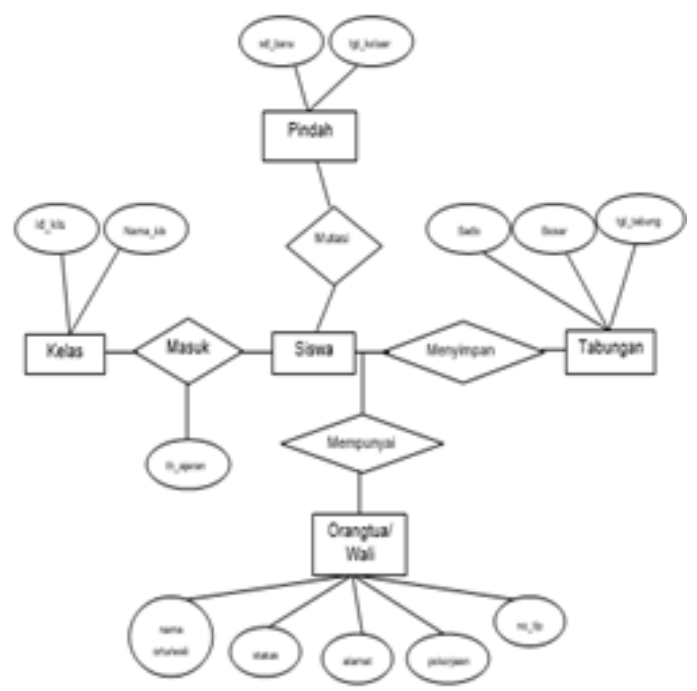

Gambar 6. ERD Tabungan Madrasah Ibtidaiyah Negeri 01 Kota Bengkulu 
Jurnal Pseudocode, Volume IV Nomor 1, Februari 2017, ISSN 2355-5920

www.ejournal.unib.ac.id/index.php/pseudocode

IV. HASIL DAN PEMBAHASAN

\section{A. Halaman Utama}

Halaman utama ini akan menyajikan semua perintah menuju form-form lainnya yang terdapat dalam aplikasi ini.

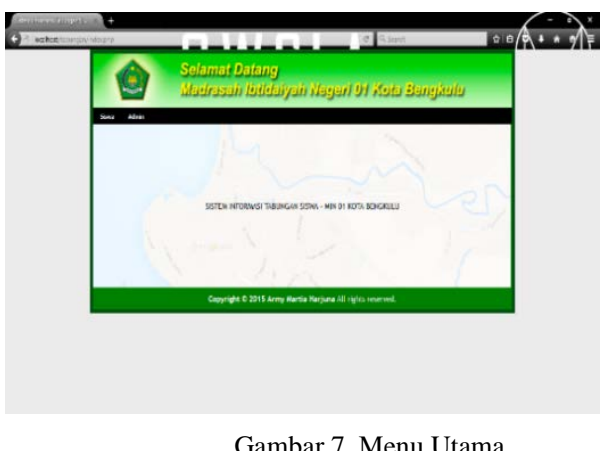

\section{B. Menu Login Admin}

Halaman login admin berfungsi sebagai kunci masuk kedalam sistem aplikasi tabungan siswa. Untuk dapat login seorang admin harus memiliki password yang sesuai dengan sistem aplikasi tabungan siswa yang ada. Jika berhasil melakukan login admin akan menuju ke halaman menu utama admin.

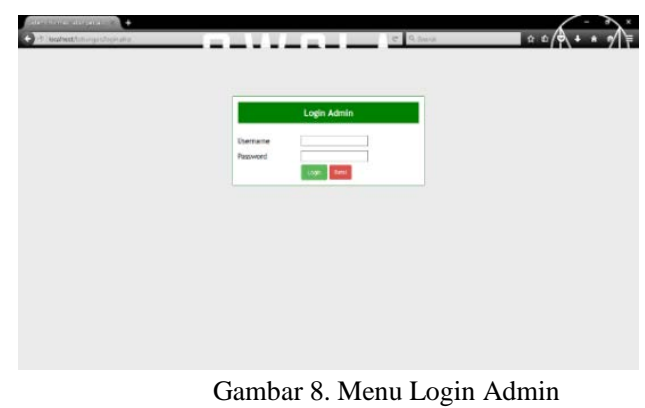

Dalam menu login terdapat inputan dan tombol, antara lain:

a. Username, digunakan sebagai teks inputan username admin.

b. Password, digunakan sebagai teks inputan password admin.

c. Tombol login, digunakan untuk memproses sinkronisasi username dan password yang diinputkan dengan username dan password yang terdapat dalam database. d. Tombol batal, digunakan untuk keluar dari halaman login dan kembali ke menu halaman utama.

1. Tampilan Menu Admin

Di dalam halaman menu admin terdapat home, input data, profil siswa, tabungan, informasi tabungan, pesan, laporan, ganti password, logout. Dan jika menu tersebut di klik, maka akan masuk ke halaman masing-masing. Di dalam menu-menu ini terdapat tabel-tabel yang akan di input nantinya dan dapat di lihat juga nama-nama yang sudah di input.

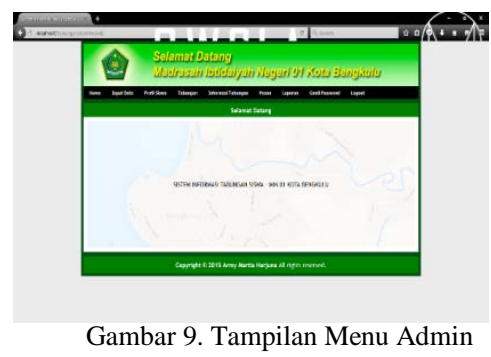

2. Menu Input Data
a. Sub Menu Kelas

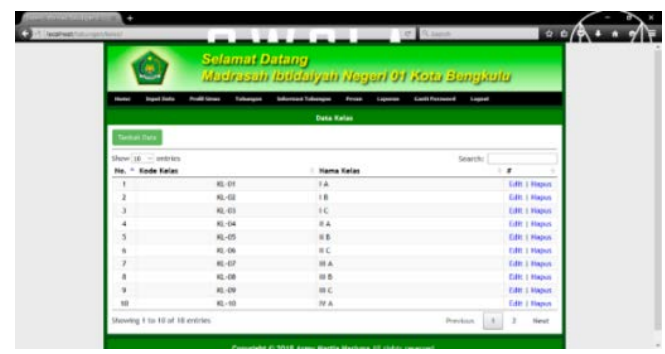

Gambar 10. Menu Input Data Kelas

b. Sub Menu Siswa

Pada proses penginputan data siswa, admin memasukan NIS, Nama Siswa, Tempat Lahir, Tanggal Lahir, Kelas, Agama, Alamat, Nama Ayah, Nama Ibu, Status Orang Tua, No. Hp, Password, Foto.

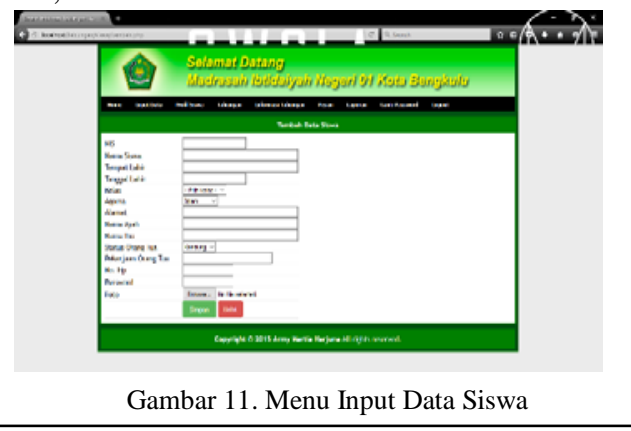


3. Menu Tabungan

a. Sub Menu Penyetoran

Menu ini digunakan untuk menginputkan data pembayaan uang tabungan sekolah.

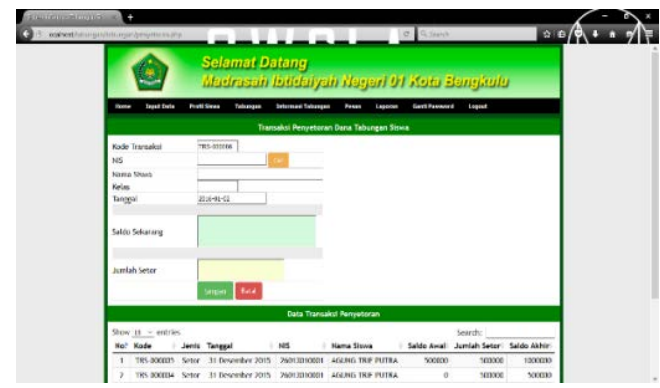

Gambar 12. Halaman Penyetoran

Pada Gambar 13 di bawah ini berfungsi untuk menu pencarian data siswa. Pada menu ini admin akan dimudahkan untuk mencari dan memperoleh data siswa yang dibutuhkan.

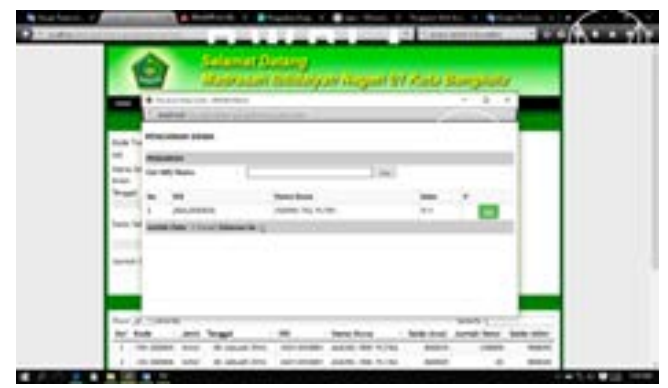

Gambar 13. Menu Pencarian Siswa

4. Sub Menu Penarikan

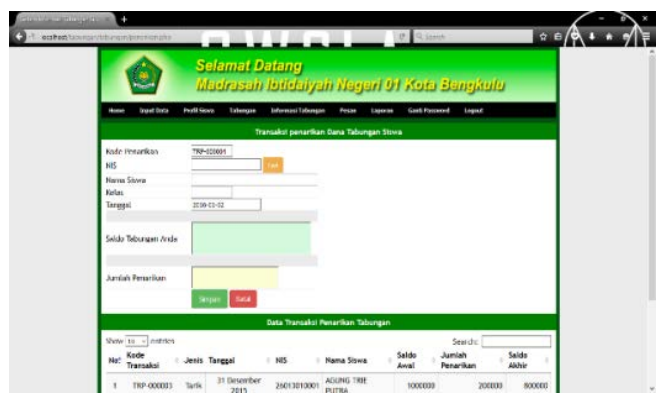

Gambar 14. Menu Penarikan

5. Menu Pesan

Pada halaman ini, aplikasi ini memberikan media komunikasi pesan. Sehingga siswa bisa berkomunikasi langsung kepada admin ataupun sebaliknya.

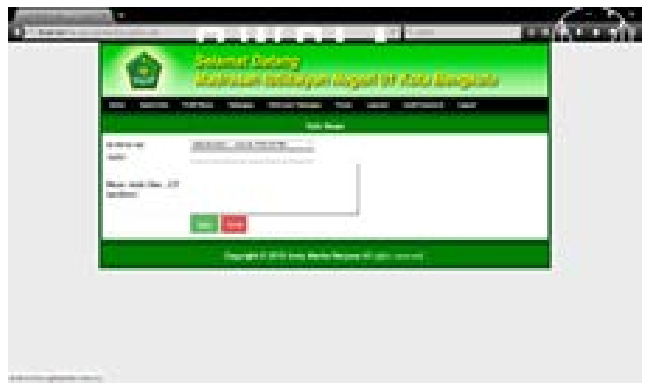

Gambar 14. Menu Pesan

6. Menu Laporan Tabungan

Menu pada halaman ini berfungsi untuk melihat laporan data siswa, laporan penyetoran dan laporan penarikan siswa. Pada halaman ini juga telah disediakan menu untuk mencetak laporan yang diinginkan.
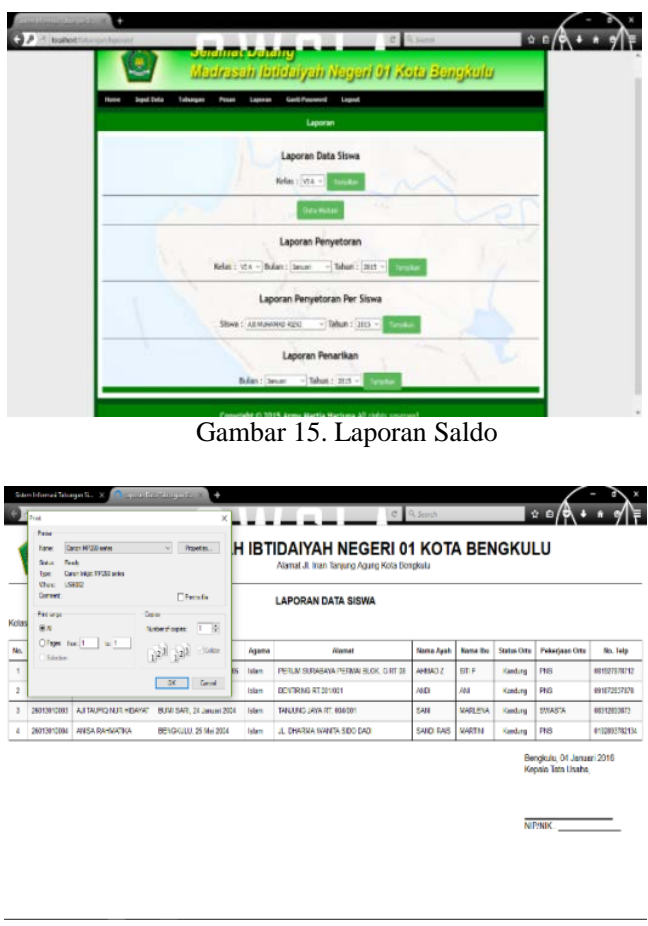

Gambar 16. Cetak Laporan

7. Menu Merubah Password Pengguna

Pada menu ini diperuntukan untuk admin untuk merubah password yang dia inginkan. Pergantian password dianjurkan dapat dilakukan sesring mungkin agar lebih terjaga keamanannya. Detai gambarnya dapat di lihat pada Gambar 17. 


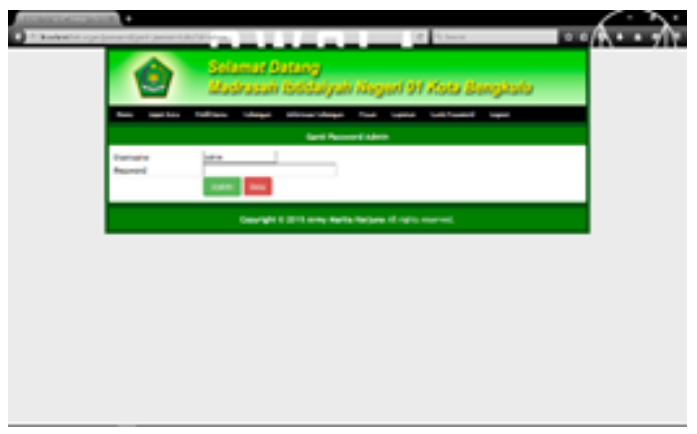

Gambar 17. Menu Ubah Password

\section{Halaman Login Untuk Siswa}

Halaman login siswa berfungsi sebagai kunci masuk kedalam sistem aplikasi tabungan siswa. Untuk dapat login seorang siswa harus memiliki password yang sesuai dengan sistem aplikasi tabungan siswa yang ada. Jika berhasil melakukan login siswa akan menuju ke halaman menu utama siswa. Tampilan halaman login siswa dapat ditunjukkan dalam Gambar 18.

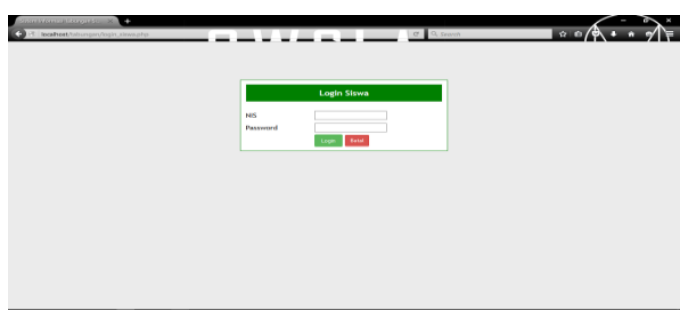

Gambar 18. Menu Login Untuk Siswa

\section{Halaman Utama Menu Untuk Siswa}

Tampilan menu siswa, siswa tidak dapat melihat apa yang ada di menu admin, siswa hanya dapat melihat profil siswa, informasi tabungan, dan pesan.

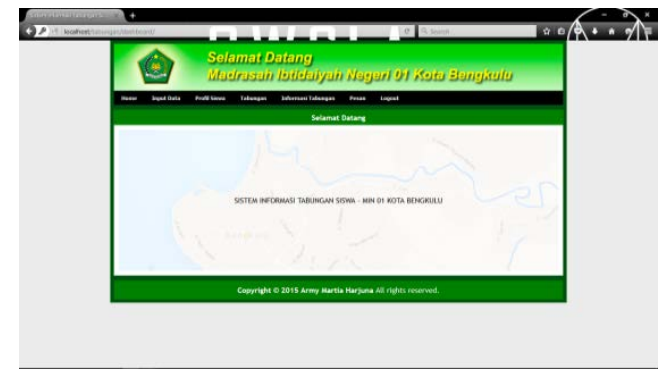

Gambar 19. Halaman Utama Pada Menu Siswa

\section{Halaman Informasi Tabungan Siswa}

Pada halaman ini siswa dapat melihat informasi riwayat tabungannya lihat pada Gambar 20.

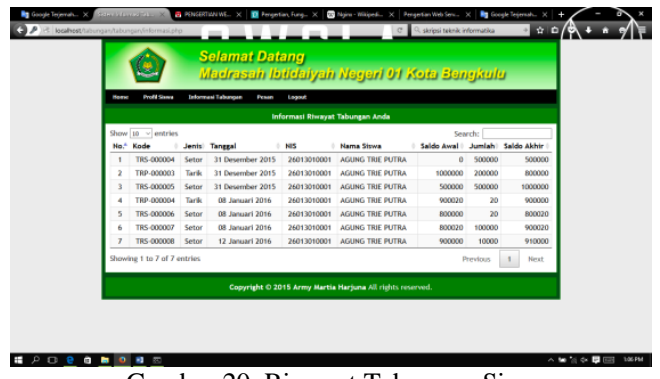

Gambar 20. Riwayat Tabungan Siswa

\section{Pengujian Sistem}

Pada aplikasi ini dilakukan pengujian Beta. Pengujian Beta merupakan pengujian yang dilakukan oleh satu atau lebih secara langsung pada pengguna aplikasi atau perangakat lunak yaitu petugas tabungan dan guru, yaitu untuk mengetahui kualitas dari perngakt lunak atau aplikasi yang telah dirancang agar sesuai dengan yang diharapkan.

\begin{tabular}{|c|c|c|c|c|c|c|}
\hline \multirow[t]{2}{*}{ No } & \multirow[t]{2}{*}{ Pertanyaan } & \multicolumn{2}{|c|}{$\begin{array}{l}\text { Katagori } \\
\text { Jawaban }\end{array}$} & \multirow{2}{*}{\begin{tabular}{|c|} 
Jumlah \\
Populasi \\
Sampel
\end{tabular}} & \multirow{2}{*}{\multicolumn{2}{|c|}{$\begin{array}{c}\text { Jumlah } \\
\text { Persentase } \\
\text { Dalam \% }\end{array}$}} \\
\hline & & $\mathrm{Ya}$ & Tidak & & & \\
\hline 1. & $\begin{array}{c}\text { Apakah } \\
\text { program } \\
\text { aplikasi } \\
\text { tabungan } \\
\text { siswa } \\
\text { diperlukan? }\end{array}$ & 8 & 2 & 10 & $80 \%$ & $20 \%$ \\
\hline 2. & $\begin{array}{c}\text { Apakah } \\
\text { aplikasi ini } \\
\text { dapat } \\
\text { membantu } \\
\text { petugas } \\
\text { tabungan? }\end{array}$ & 9 & 1 & 10 & $90 \%$ & $10 \%$ \\
\hline 3. & $\begin{array}{c}\text { Apakah } \\
\text { aplikasi ini } \\
\text { sesuai } \\
\text { dengan } \\
\text { yang } \\
\text { diharapkan? }\end{array}$ & 8 & $\overline{2}$ & $\overline{10}$ & $80 \%$ & $\overline{10} \%$ \\
\hline 4. & $\begin{array}{c}\text { Apakah } \\
\text { aplikasi ini } \\
\text { sesuai } \\
\text { dengan } \\
\text { sistem yang } \\
\text { berjalan } \\
\text { saat ini? }\end{array}$ & 8 & 2 & 10 & $80 \%$ & $10 \%$ \\
\hline 5. & $\begin{array}{c}\text { Apakah } \\
\text { tampilan } \\
\text { dari tata } \\
\text { letak } \\
\text { aplikasi ini } \\
\text { mudah } \\
\text { digunakan? }\end{array}$ & 7 & $\overline{3}$ & 10 & $70 \%$ & $10 \%$ \\
\hline
\end{tabular}


Jurnal Pseudocode, Volume IV Nomor 1, Februari 2017, ISSN 2355-5920

www.ejournal.unib.ac.id/index.php/pseudocode

Berdasarkan indikator-indikator yang terdapat pada tabel 4.1. maka dapat ditarik kesimpulan nilai rata-rata tingkat keberhasilan dan kepuasan terhadap pernakaian perangkat lunak yang dihasilkan sebesar $80 \%$.

\section{KESIMPULAN}

Adapun kesimpulan yang telah diuraikan pada tulisan diatas adalah begitu pesatnya perkembangan teknologi semakin kedepan semakin maju, dengan ini penulis ingin membuat suatu hal yang lebih modern, mengubah sistem yang selama ini manual menjadi terkomputerisasi sehingga dapat membantu memudahkan orang dalam pekerjaannya. Berdasarkan kajian serta tinjauan teori yang dimiliki serta dari hasil analisis dan perancangan pengelolaan data Tabungan Siswa di Madrasah Ibtidayah Negeri 01 Kota Bengkulu.

Dari hasil pembahasan tentang perencanaan sistem basis data tabungan menggunakan servernginx maka diambil kesimpulan:

1. Dengan adanya web ini maka pihak sekolah dapat lebih mudah menyajikan informasi tentang tabungan sekolah.
2. Proses pengolahan data dan pencarian data dan informasi menjadi lebih mudah serta proses penarikan dan penyetoran yang otomatis akan menghitung.

3. Keamanan data terjamin karena dalam aplikasi ini tersedia form Login sehingga tidak semua user dapat membuka program ini tanpa izin dan memudahkan pembuatan laporan dalam kurun waktu tertentu yang dapat langsung dicetak.

\section{REFERENSI}

[1] Hapsari, S., dkk. Rancang Bangun System Informasi Pembayaran Dan Tabungan Siswa Pada Bank Mini Artha Mandiri Sekolah Menengah Kejuruan (SMK) Negeri Pringkuku Pacitan. Journal Speed - Sentra Penelitian Engineering Dan Edukasi-ijns.org,10, 2011.

[2] Purnama, H., dkk. Perancangan Program Aplikasi Tabungan Siswa Sekolah Dasar Negeri Cipancar IV Dengan Menggunkan Pendekatan Metodologi Rapid Application Development. Jurnal Algoritma Sekolah Tinggi Teknologi Garut. ISNN: 2302-7339 vol.11. 2014.

[3] Fathansyah. Basis Data. Bandung: Penertbit Informatika. 2012.

[4] Lukitasari, H., dkk. Analisis Perbandingan Load Balancing Web Server Tunggal Dengan Web Server Cluster Menggunkan Linux Virtual Server. Universitas sriwijaya. Vol.5 no.2. 2010.

[5] Aivaliotis, D. Mastering Nginx. Birmigham: Packt Publishing Ltd. 2013.

[6] Jamaludin. Cepat Mahir ASP.NET3.5. Yogyakarta: ANDI. 2009. 